\title{
eProcurement for Industrial Maintenance Services
}

\author{
Maik Herfurth, Axel Meinhardt, Jörg Schumacher, and Peter Weiß \\ FZI Research Center for Information Technology, Haid-und-Neu-Straße 10-14, \\ D-76131 Karlsruhe, Germany \\ \{herfurth, meinhardt, schumach, weiss\}@fzi.de
}

\begin{abstract}
E-procurement solutions can deliver great cost-saving potential for purchasing. But services have not generally been considered as a part of these cost-saving measures. The process of service procurement is often argued to be more complex and less standardized than material procurement. In this paper we propose solutions and standards for service procurement.
\end{abstract}

Keywords: Service Procurement, Service Specification, Service Classification, eProcurement.

\section{Introduction}

The paper looks at interoperability issues in the context of e-procurement for industrial maintenance services and asset management. The maintenance of industry facilities and assets challenges currently industry. The components of e-procurement are: back-end-system of buyer, e-proprocurement-system of buyer, electronic catalogs for service specifications and back-end-system of seller. E-Procurement can be further subdivided into e-ordering and e-sourcing in correspondence with its support to operational procurement and strategic procurement. More precisely, e-ordering is aimed at the realization of faster, easier and decentralized operational procurement processes at least possible cost which echoes the fact that e-ordering concentrates on reduction of procurement process costs. Today's, addressed industry domain is lacking shared e-business standards which allow classification of product data, customer data, material data, etc.. Known standards are UNSPSC [19] and eCl@ss [18] which intend to improve electronic data exchange between business partners. Corporate data management and master data management along the value chain are thus hot topics in industry today [14]. We will identify that standardization and harmonization of e-business solutions require harmonized business processes, good data quality and precise definitions of interfaces.

\section{Objectives}

Industrial services compass a high volume at industrial companies, mostly up to 50 per cent of total procurement volume. Therefore service processes cause actually high costs in most companies. But because of the high complexity of service products, there weren't a lot of attempts to achieve cost saving with electronic business transfer 
in this area. For the procurement of services, e-business processes are barely distinct and standardized as with pure material products. There is no standardized electronic trading by means of a catalogue like for material. Integrative, systematic e-business procedures and interfaces are missing to execute the electronic data exchange of services inclusive used material between customers and suppliers in a standardized way. The paper derives requirements for service procurement from a real life scenario of supply chains for industrial maintenance services at hand. We look at supply chains of small service providers which offer industrial maintenance services to large often globally operating companies. It is analyzed, how procurement for services can be described and automated using e-business standards and harmonized descriptions. Incipiently, basic concepts, definitions, historical backgrounds and examples of relevant subject areas are introduced. This includes in particular the general procurement, characteristics of services, ways to model a business and technical aspects. Furthermore, requirements for describing the organization of a business, the work process, the emerging data and the implementation in information technology are presented.

\section{State-of-the-Art}

This section provides a brief overview of state-of-the-art and related work. We outline existing challenges and limitations as well as shortfalls of current applications, solutions and approaches of service procurement. The reader gets acquainted with basic definitions and core concepts.

E-procurement supports the strategic- and operational procurement with electronic means to optimize the purchasing process taking into account the key indexes of process cost and process results [12]. The procurement process can be divided into strategic procurement and operational procurement according to different procurement tasks. Strategic procurement encompasses those, which undertake the function of forming general procurement conditions and configurations in order to create premises for operational procurement and to improve the operating efficiency of procurement from a centralized perspective. Operational procurement comprehends contrarily concrete transaction processing and places its emphasis on satisfying needs on specific objects in time rather than contributing to the procurement strategy. Service Procurement implicates its own challenges to be looked into in the remainder.

\section{1 eBusiness and Industrial Maintenance}

Industrial Maintenance is "the combination of all technical, administrative and managerial actions during the life cycle of an item intended to retain it in, or restore it to, a state in which it can perform the required function" [13]. Industrial maintenance belongs to the category of indirect products. Indirect procurement can be further divided into two kinds: ORM (Office Products and Travel Services) and MOR (Maintenance, Repair and Operating) [23]. The former refers to goods and services required in the administrative area to keep routine operation of company. The latter includes besides the overhaul and maintenance items also materials for research and development. In 
the remainder we shall look in particular at the latter, procurement of indirect services and related products. A variety of standards address areas related to e-procurement, like identification, classification, categorization, communication and process management. Most of those approaches focus on information about physical products. Eprocurement processes as service procurement processes can be seen and classified in two different objectives: the public (external) processes and the private (internal) processes. The public processes are characterized by their type of collaboration with different stakeholders. They are performed outside of the borders of the organization. The participants in these processes are suppliers in a supply chain scenario, partners in a virtual enterprise scenario and customers in a B2B scenario. Private processes are characterized by its internal focus within an enterprise. They are performed within a company by its organization. In our scenario we focus on suppliers of industrial maintenance service processes and customers from the industry. Related work can be found in [1] [2] [3] [4] [5] [7] [8] [9] [10] [11]. Products and Services Categorization Standards (PSCS) are flourishing as they seem to offer to overcome organizational and IT system barriers. PSCS are reflecting domain consensus about how products or services can be grouped and described.

\subsection{Service Procurement}

For manufacturing companies, the procurement has an important role. Every Euro which can be saved with the purchasing of goods and services, doesn't have to be generated as additional earning. The savings of procurement will be reflected directly in the success of the company. But for the procurement of services, it is a different picture: in catalogue systems and service specifications, there is only a summarized position for services along with the wide structure for articles. This entails a lack of transparency of costs for the services. But the expenditure for services is rising: services for cleaning service, facility management as well as maintenance and reparation. The consequences are raising expenses for service for the whole company. Besides material procurement, service procurement is the most requested good. In our days material procurement and ebusiness collaborate closely and a lot of software solution like ERP systems are on the market to provide ebusiness solutions. The standardization of material and goods reached a high grade. Since the capacity of service is continuously growing, the demand after standardized services is getting stronger and also ebusiness solution for service procurement. Service procurement is subject to certain problems and conditions. There are no equalized general purchasing conditions for services, no standards because of their complexity. In case that contents of delivered services are hybrid, combining material with service delivery (such as maintenance and repair of assets), the complexity of cases even increases.

\section{Research Approach}

The following section explains the elements of our approach and how we expect to solve identified problems and overcome existing barriers of service procurement. Our 
analysis of requirements for electronic description and transaction of service procurement is based on real use cases based on different service procurements scenarios. We analyzed and defined 12 different service procurement use case between large industry clients and small and medium sized companies as service providers. For the definition of requirements, we analyzed the supply chain and the internal and external processes and master data to derive a common understanding of a standard process and interfaces.

\subsection{Definition of Industrial Services}

To find solutions for the challenges in our research approach, we have to achieve specific goals and milestones. One of the most important issues is the definition and characterization of services. Services types have to be analyzed, structurized and classified. As a result of our pre analysis of services in the maintenance area we can define now by factors the characteristics of services and their execution. The first factor is the performance. The performance of the service can either be immaterial and material (combined) or only immaterial. The second factor transaction of the specification can be described by its subcomponents attributes and information. Other important factors are the calculation, combinations of systems and rules and the documentation. By using these factors we can classify all the different types of services to specify them. Also the transaction of services can be described by specific factors. As an important factor, the type of a service can be seen. The type can be either an individual single intervention or depending on a frame contract. As a factor the services can be distinguished by their area of application which can either be the industrial maintenance area or the disposal area. The factor transaction types defines the variants of the transaction of a service. The factor trigger defines the subcomponents maintenance strategy and the parameter value which correspond together. Maintenance strategy specifies the kind of the maintenance type in terms of the strategy and it can be defined more carefully by the parameter value. The assignment, the placing and the transaction of industrial services can be described by its internal or external handling. Other factors and criteria are the acceptance, the accounting, the combination of systems and rules, the warranty, the documentation and the partners and permits. The characterization of the description and transaction of industrial services by these factors support the classification of industrial services.

\subsection{Data Model for the Description and Specification of Services}

In order to describe and specify the structure of services in a formal way, we are going to define data models for the specific factors of services. The definition of data models are the pre-stage to transform the data model into a formal description based on XML, so-called ebus-XML. The structure defines the characteristics of services and specifies the transaction of services within a workflow of services processes. Figure 1 shows our predefined data model for the specification of services units. The approach allows specifying and maintaining complex service specifications which in practice comprise in average more than 15,000 positions. Another strand to be looked into is the standardization of service specifications inside large, multinational enterprises. 


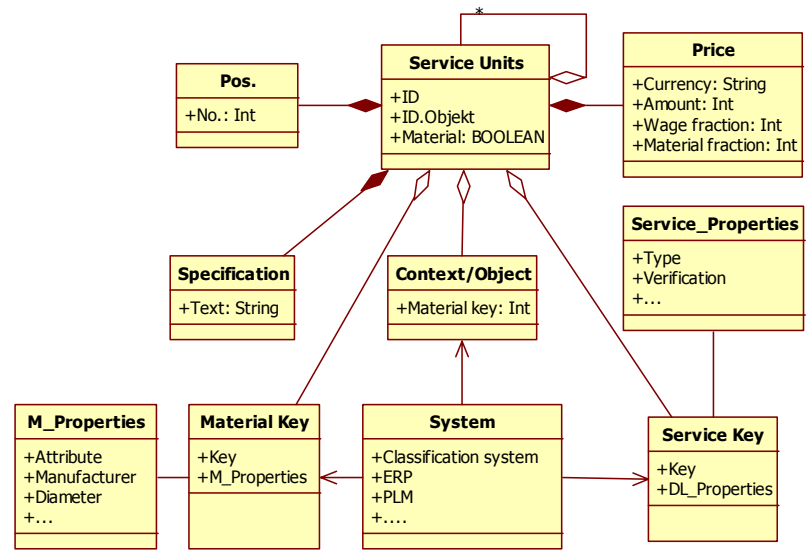

Fig. 1. Data Model for the specification of a Service Unit

In order to execute ebusiness processes for the procurement of industrial maintenance services, maintenance services have to be classified and structured to fulfill the requirements for electronic data exchange. A standardized description of service data lead to their classification among most accepted existing standards such as eCl@ss or UNSPC [18] [19] [20] [21]. For the procurement of material different kind of standards are already existing. Therefore an exact classification and description is implemented and master data for the procurement of services can be derived in a high quality for the purpose of ebusiness transactions.

\subsection{Reference Process for the Transaction of Industrial Services}

At the same time the execution of services has to be analyzed to understand the type of service. The specification and characteristics of services correspond closely to the transaction of them. By analyzing the different kind of transactions in this domain we defined a reference meta process for the procurement of services. The reference process concludes all the use case descriptions and analysis based on our research. By using our own defined meta language, we defined the reference process on different layers for different level of abstraction. The process describes the performance of eprocurement of services and visualizes the views of the service provider and the service customer. On a high abstract level, we defined the most important milestones within the process. On a second abstraction layer we model the individual characteristics of the procurement process of different services (see Figure 2). Based on the reference process we develop a configuration framework for services based on different characteristics of services. It defines the execution of services depending on different factors. Sub-processes can be called and combined in different ways. Along the flexible configuration of the execution of ebusiness service processes, the processes have to be implemented into an IT architecture. As a solution we use a centralized solution based on a catalogue system and an ERP system to connect the service providers and the service customers. Because of the nature of services and its need of interaction and communication between the customer and the service provider, an interactive 


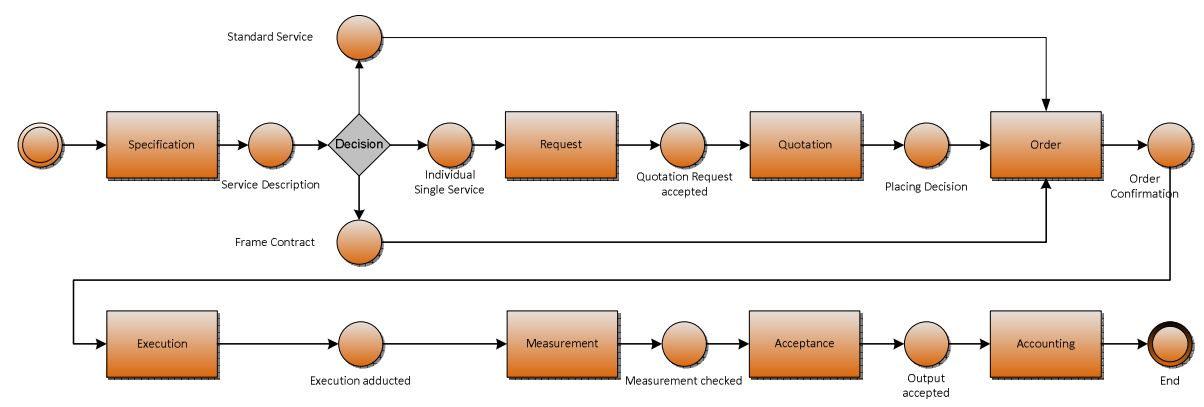

Fig. 2. Standardized service processing and transaction

shopping basket will be realized in order to reduce the communication cycles and to lower the transaction costs. The execution of sub-processes will be realized by a service oriented architecture (SOA). Depending on rules and logic, services can be called and triggered to perform.

\section{Results}

E-procurement of services can be described by four dimensions: (1) service, (2) characteristics of services, (3) IT solution and (4) electronic execution of service processes. Standardized descriptions lead to a deep integration with a high flexibility of service descriptions and are a precondition of flexible configurations of services. Therefore the IT solution in combination with the factors service and the characteristics of services build the fundamental basis for the electronic transaction of service processes. For the individual standardized execution of service procurement processes a Meta reference process have to be defined for the different kind of service procurement execution types. The Meta reference process can be configured depending on the factors describing the services and the service procurement processes based on its characteristics its description and execution.

After our analysis we can conclude that ebusiness of service processes in general can be formalized by certain dimensions. The description of services and the electronic transaction of services are based on these four dimensions (see Figure 3). These four factors define the relation and interdependence of the nature of services for its electronic transaction.

(1) Service. The service itself has to be described by a standardised description of services. With these formal descriptions, catalogue structures and performance specifications can be derived. With this structure, a profound integration of services with high flexibility can be reached and used for added value networks and collaboration networks.

(2) Description of Services. Specific factors can be used for the specification and description of services. These factors are properties of services and specify the typical behaviour and the kind of service. These factors are used to specify the services as well as to define the execution of services. 


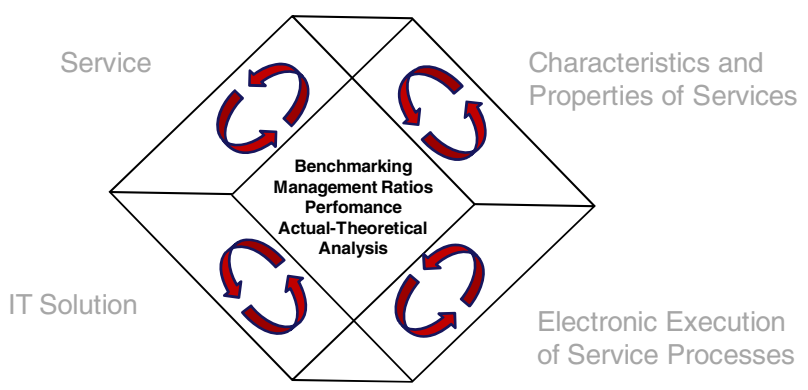

Fig. 3. Inducing intelligence in cross-organizational service procurement processes

(3) IT Solution. The IT system solution supports the definition and description of services to allow for their execution meaning the electronic description and execution of service master data. The IT solution provides a structure for catalogues and for performance specifications combined with a centralized portal solution.

(4) Service Processes. Service processes can be derived and executed based on the IT Solution, the service and the service description. The execution of service processes goes along with a meta process as a reference process for the service description and execution. A service process can be seen as an instance of the meta process, specified depending on its properties and configured by sub-processes based on the SOA.

\section{Summary and Conclusions}

E-procurement solutions can deliver great cost-saving potential for purchasing. But services have not generally been considered as a part of these cost-saving measures. The reasons at hand are manifold. Lack of standardized service descriptions and thereof resulting lack of transparency of services ("make or buy"-decisions are costly and vague) are most prioritized Service procurement requires collaborative business processes and a common view on exchanged business objects and data. Data quality is a major issue as it determines finally effectiveness and efficiency of IT systems and applications. Our test bed will allow a proof concept and a continuous evaluation of proposed IT solution and related results closely with the users. Further issues to be looked into are change management and methods for comparison of internal services with external service offerings. New concepts and paradigms as Service Oriented Architectures (SOA) and a need of integrated IT applications (within companies for analytical business applications such as data warehouses, business intelligence applications) require new ways of governance and e-business standards (such as classification systems) to achieve data quality in supply chains. Moving toward flexible SOA architectures often faces difficulties in information management and integration challenges.

\section{References}

1. Verbeek, H.M.W., Hirnschall, A., van der Aalst, W.M.P.: XRL/Flower: Supporting InterOrganizational Workflows Using XML/Petri-net technology (2002)

2. van der Aalst, W.M.P.: loosely Coupled interorganizational Workflow: modelling and Analyzing Workflows Crossing Organizational Boundaries. Information and Management 37(2), 67-75 (2000) 
3. van der Aalst, W.M.P.: Process-oriented Architectures for Electronic Commerce and Interorganizational Workflow. Information Systems 24(8), 639-671 (2000)

4. Grefen, P., Aberer, K., Hoffner, Y., Ludwig, H.: CrossFlow: Cross-organizational Workflow Management in Dynamic Virtual Enterprises. International Journal of Computer Systems, Science and Engineering 15(5), 277-290 (2001)

5. Lazcano, A., Alonso, G., Schuldt, H., Schuler, C.: The WISE Approach to Electronic Commerce. International Journal of Computer Systems, Science and Engineering 15(5), 345-357 (2001)

6. Yan, H., Bejan, A.: Modelling workflow within distributed systems. In: Proceedings of International CSCW Conference (2001)

7. Bons, R.W.H., Lee, R.M., Wagenaar, R.W.: Designing trustworthy interorganizational trade procedures for open electronic commerce. International Journal of Electronic Commerce 2, 61-83 (1998)

8. Frank, L., Wolfgang, D.: Modelling inter-organizational processes with process model fragments. In: Proceedings of the Workshop Informatik (1999)

9. van der Aaalst, W.M.P., Anyanwu, K.: Inheritance of Interorganizational Workflows to Enable Business-to-Business E-commerce. In: Proceedings of the Second International Conference on Telecommunications and Electronic Commerce (1999)

10. Lin, D.: Compatibility Analysis of Local Process Views in Interorganizational Workflow. In: 9th IEEE International Conference on E-Commerce (2007)

11. Larsen, M.H., Klischewski, R.: Process Ownership Challenges in IT-Enabled Transformation of Interoganizational Business Processes. In: Proceedings of the 37th Hawaii International Conference on System Sciences (2004)

12. Stoll, P.P.: E-Procurement-Grundlagen: Standards und Situation am Markt. 1. Auflage, Wiesbaden (2007)

13. Maintenance - Maintenance terminology; European standard: German and English version prEN 13306:2008; DIN EN 13306:2001-09 (2008), http : / / www. din. de

14. Master Data Management: Consensus-Driven Data Definitions for Cross-Application Consistency, Philip Russom, TDWI (The Data Warehouse Institute) (October 2006)

15. Bartels, A.: Services Procurement Grows Despite Obstacles, third document in ePurchasing Market, Forrester (2007)

16. Kock, N., D'Arcy, J.: Resolving the e-collaboration paradox: The competing influences of media naturalness and compensatory adaptio. Information Management and Consulting, Special Issue on Electronic Collaboration 17(4), P72-P78 (2002)

17. Kock, N., Nosek, J.: Expanding the Boundaries of E-Collaboration. IEEE Transactions on professional communication 48(1), P1-P10 (2005)

18. ECl@ss: International Standard for the Classification and Description of Products and Services (2009), http: / / www . eclass . eu /

19. UNSPSC (2009), http: / / www . unspsc . org

20. eOTD (2009), http: / / www . eotd. org

21. RosettaNet Technical Dictionary (2009), http: / / www . rosettanet.org

22. eBusInstand, 2009: Service procurement for industrial maintenance (2009), http: / / www . ebusinstand. de

23. Neef, D.: E-Procurement: from Strategy to Implementation, 1. Auflage, London (2001) 